\title{
Teoría de la justicia y ámbito doméstico
}

\author{
RAMÓN VARGAS-MACHUCA ORTEGA \\ Universidad de Cádiz
}

Desde hace más de veinticinco años una amplia literatura sobre teorías de la justicia viene proporcionando criterios en abundancia para promover igualdades o tratar diferencias, para asignar derechos o deberes, para, a fin de cuentas, determinar una u otra distribución de beneficios y cargas. Por eso sorprende la poca información que las más influyentes teorías de la justicia han deparado acerca de las desigualdades por razón del sexo y consiguiente distribución de ventajas y desventajas en el ámbito doméstico, a pesar de ser algo determinante para la configuración $\mathrm{dc}$ oportumidades y expectativas de mujeres y hombres. El silencio de las concepciones de la justicia sobre las relaciones en el ámbito doméstico se ajusta a la idea de que las prescripciones de una concepción de la justicia sólo afectan a lo que se considera incluido en la esfera de lo público (el dominio de lo político y lo cconómico) y no a lo que se supone pertenece a la esfera de lo privado (la familia, el dominio de lo doméstico y personal). Se ha creído en nombre de una idealizada visión de la familia que la justicia no cs virtud idónea para el ámbito familiar. Como resultado, la existencia de jerarquías abusivas, malos tratos o desigualdad de oportunidades en el seno de la familia, en una palabra, la realidad de la dominación en el ámbito doméstico, no ha estado casi nunca cn la agenda de las más influyentes teorías de la justicia.

Pero ies posible, como ya se preguntara Stuart Mill ${ }^{3}$, una sociedad justa sin una familia justa? La hipótesis, a cuyo desarrollo se dedicarán los próximos comentarios. es la siguiente: la exclusión del ámbito doméstico de la aplicación de principios de justicia es en la actualidad el talón de Aquiles de nuestros más reconocidos patrones de justicia; por ello, la crítica feminista de esta omisión constituye un refuerzo informativo ${ }^{2}$ para las concepciones de la justicia que se han inspirado en la tradición liberal-igualitaria y que son el asiento constitucional de la mayoría de las democracias existentes.

\section{Feminismo y liberalismo igualitano}

El feminismo, además de movimiento social, es una tradición de pensamiento, cuya inspiración básica bien podría encontrarse en ese recelo que todas las corrientes feministas comparten ante la vocacion universalista de la ética ilustrada, ya que sospechan que ésta se ha limitado a convertir el punto de vista del varón en estándar moral para todos ${ }^{3}$. Más allá de compartir la sospecha de la masculinización de lo éti$\mathrm{CO}$, el panorama feminista resulta muy variado. Por eso deberíamos aclarar qué rasgos del proyecto feminista contribuyen a mejorar una concepción de la justicia como la democrática, cuyas características también convendría repasar más que dar por supuesto.

El feminismo como movimiento social tomó auge con el desarrollo del capitalismo. Los cambios en los modos de vida y el desarrollo del conocimiento y la cultura han venido minando loda justificación de una distribución de funciones sociales por razón del género y basada en las diferencias biológicas entre hombre y mujer. Así, en primer lugar, el que la mujer haya 
vivido principalmente confinada en la esfera doméstica como agente de la reproducción ha sido el resultado histórico de los diferentes sistemas de parentesco y de las distintas modalidades de división sexual del trabajo y no la consecuencia de una determinación «natural» ${ }^{4}$, En segundo lugar, el que se hayan mantenido ocultas las desigualdades de recursos y de poder que se dan en el ámbito doméstico hay que achacarlo a que la tradición ética en general, $y$ las teorías de la justicia en particular, se desentendieron del ámbito doméstico en nombre del principio de que a la justicia compete lo público y no lo privado ${ }^{5}$. En tercer lugar, la inserción de la mujer al mundo productivo se ha ido produciendo parcial y tangencialmente, constituyendo en una gran proporción una fuerza de trabajo dc reserva y marginal. Por último, y con independencia de su posición en la esfera de lo público y el valor de su trabajo remunerado en el ámbito laboral, la mujer ha seguido llevando el peso y la responsabilidad de todo lo relacionado con el mundo de la reproducción y la atención de los seres cercanos. Sin embargo, cl cuidado de pequeños, mayores y enfermos, el trabajo propiamente doméstico y tantas otras formas de sostener la calidad de vida de los demás, funciones que por lo común realizan las mujeres, no cuentan socialmente, es trabajo impagado ${ }^{\circ}$.

La crítica feminista, que ha desvelado los síntomas de la desvalorización social de aquellas funciones en las que se ha concentrado la mayor parte de la fuerza de trabajo femenina, va más allá y encuentra en la sexualidad, tal como está instituida socialmente, un ingrediente de primera importancia para reproducir la subordinación de la mujer al hombre ${ }^{7}$. El género, que era un término al que en rcalidad sólo prestamos atención en su acepción gramatical, resulta un patrón de distribución del poder y estratificación social que perpetúa la desigualdad de oportunidades cntre hombres y mujeres. Asî lo explica Susan M. Okin:

"Lo que pretendo significar, cuando digo que el matrimonio estructurado según los papeles atribuidos a sus componentes por razón del géncro hace vulnerable a las mujeres, es lo siguiente: Esa distribución de funciones no es fruto de una necesidad natural como alguna gente cree. Nada en la naturaleza determina que los hombres no tengan una participación igual en cl cuidado de los niños. Nada en la naturaleza del trabajo hace imposible adecuarlo al hecho de que la gente además de empleados son padres. El que esto no haya ocurrido es en parte consecuencia de esa diferenciación entre los sexos construida social c históricamente que las feministas han venido en llamar género. Vivimos en una sociedad que durante siglos ha convertido las características innatas de los sexos en uno de los más claros factores legitimizadores, tanto formal como informalmente, de una diferente distribución de derechos y restricciones" $"$.

El género, pues, es un factor social de la mayor importancia. La crítica feminista al rescatarlo de su anonimato y aparente neutralidad lo convierte en una fuente do crítica sustantiva de la distribución del poder social. Buena parte de esa crítica se ha levantado, a pesar de todo, sobre principios y valores de la tradición ilustrada liberal, tales como que los humanos deben ser considerados básicamente iguales independientemente de su posición, dotes y méritos, y deben disponer de ciertas condiciones materiales, autonomia personal, derechos y oportunidades que les permitan desarrollar sus propias capacidades y obtener de los bienes disponibles el rendimiento más valioso?

La inspiración igualitaria en el seno de la tradición liberal surgió más bien como un ideal de protesta que fue levantando actas de los incumplimientos de la utopía liberal $\mathrm{y}$ de las deficientes realizaciones producidas en su nombre. En ese sentido el pensamiento feminista ha sido una de 
tantas "revucltas contra el destino" que han caracterizado a todos los movimicntos de emancipación igualitaria. En el caso del feminismo la protesta se ha levantado contra los incumplimientos de un programa que predicaba libertad e igualdad para todos, pero que se ha ido abriendo paso al precio de excluir de ese «todos» a la mitad de la especie cuya situación ha, simplemente, ignorado. De ese modo este feminismo igualitario se ha constituido en autocrítica del desarrollo moral de la especie, demandando a la conciencia liberal el que por ser mujer no sea un problema para ser plenamente individuo ${ }^{10}$. Por tanto, ni en la raíz de la tradición igualitaria ilustrada, ni en la base del movimiento feminista hay históricamente un sustrato moral contrapuesto al del liberalismo. Lo que esta clase de feminismo ha pretendido es un mayor progreso moral por la vía de generalizar los valores de aquella tradición, poniéndolos al alcance de más individuos de la especie, volviendo más creíble la vocación universalizadora de los principios liberales y más real su razón igualitaria. De esta manera el «feminismo ético de la igualdad» representa un refuerzo importante de legitimación para los objetivos del liberalismo moral ${ }^{11}$.

\section{Acomodar las diferencias como estrategia moral}

El recelo de algunas corrientes del movimiento feminista hacia el universalismo liberal-igualitario se concreta en que o bien lo consideran aparente o bien uniformizador. En el primer caso el feminismo denuncia que esa supuesta universalidad de las pautas liberales oculta la subyugación de las mujeres. Así, por ejemplo, las reglas del Derecho, argumenta una cierta crítica feminista radical de inspiración marxista, aparentemente neutrales e imparciales, como la legislación sobre la familia, la normativa sobre la pornografía o la doctrina del consentimiento en la violación, son más bien expresiones de los puntos de vista de quienes han dirigido el sistema legal, es decir, los hombres. El Derecho, al consagrar el status quo y legitimar un tratamiento diferenciador por razones de sexo, hace invisible el dominio del hombre sobre la mujer y convierte la dominación en diferencia, la coerción legitimada en consenso y la política neutralizada er moral ${ }^{12}$. Así entendido, el feminismo se superpone a lo que en el ámbito de la cultura jurídica se ha venido en llamar «escuela crítica del Derecho" ${ }^{13}$.

En el segundo caso, de una mayor resonancia en la actualidad, el recelo de un sector del movimiento feminista hacia la concepción liberal-igualitaria de la justicia se funda en que la igualdad de trato que aquélla consagra destruye la identidad propia de las mujeres y ahoga la potencia y singularidad, tanto de la experiencia pasada y presente de las mujeres como de sus aspiraciones de futuro. El universalismo de los principios liberales es insensible a las diferencias entre los grupos y al pluralismo de valores consecuente con esa diversidad. De su pretensión por uniformar esa variedad de identidades sólo se derivan formas de represión y anulación de las kotras colectividades concretas» ${ }^{14}$.

Al calor de esa filosofía de la diferencia toma auge la contraposición entre una «ética del cuidado» propia de las mujeres y una «ética liberal de la justicia» más propia para hombres. El punto de vista moral de las mujcres está más oricntado a las relaciones personales y a la atención de los individuos concretos en contraste con la perspectiva más abstracta de los varones. Frente a los valores de una justicia liberal la «ética del cuidado» promociona valores basados en la experiencia de las mujeres en tanto que tales, como, por ejemplo, la maternidad o el cuidado de los otros en el seno de la familia. La recomendación 
que se hace entonces al movimiento feminista es la de construír un nuevo modelo de política sobre los valores del amor, el cariño y la amistad ${ }^{15}$. De este modo, un sector del feminismo, animado ahora por el último urevival antiliberal» y arropado por las corrientes éticas comunitaristas, ha creído resolver el kdilema de la diferencia» ${ }^{16}$, estableciendo la existencia de dos esencias, la del hombre y la de la mujer, distintos derechos para cada género y dos clases de ciudadanía, la masculina y la femenina ${ }^{17}$.

Paradójicamente, al efeminismo de la diferencia» le ha ocurrido, si bien con propósitos contrapuestos, lo que al igualitarismo antiliberal: ni uno ni otro han comprendido que el compromiso del liberalismo con la idea de una igualdad básica de los humanos es originariamente un intento por acomodar las diferencias y no propensión hacia una nivelación indeseable o uniformismo imposible. La idea de Locke en Letter Conceming Toleration para salvaguardar el pluralismo moral y religioso era la de "poner entre paréntesis" las diferencias entre individuos y grupos, y constituir un orden político sobre principios y valores compartidos a fin de regular la interacción social de un modo que fuera aceptable para todos los participantes ${ }^{18}$. Así, el presupuesto básico de la estrategia liberal para acomodar las diferencias fue crear un marco de derechos individuales, dentro del que pudiera florecer el pluralismo de individuos y grupos, convivir diferentes concepciones del bien moral, culturales, religiosas, étnicas, etc.

En la actualidad, la enorme diversidad de ideales de svida buena» ha vuelto más intensa la presencia del pluralismo y hace muy improbable que los individuos de comunidades amplias compartan una misma concepción de lo moralmente bueno o un mismo ideal de autorrealización. La disposición ética para identificar un bien básico o apreciar un estado social valioso la obtenemos hoy en dia más por delimitación negativa, es decir, por lo que echamos en falta y podía darse o por la percepción de lo que discrimina y agravia ${ }^{19}$. En consecuencia, es el reconocimicnto de nuestra vulnerabilidad y la consecuente necesidad de protegernos lo que hace irrebasable el principio liberal por el que tratamos de establecer ciertas normas y derechos básicos para todos (universales) y cada uno (individuales). Tales derechos pueden resumirse en la capacidad de los individuos para acciones autónomas $\longrightarrow$ ption rights - y en la disposición de unos recursos básicos - welfare rights - sin los que los individuos no pueden desarrollar sus capacidades como agentes ${ }^{20}$.

En la estrategia liberal los derechos de los grupos o la reclamación de éstos a un trato preferencial no pueden contradecir los requisitos aludidos más arriba de universalismo e individualismo. Si determinados individuos por pertenecer a un grupo social concreto han soportado históricamente deswentajas, o por su adscripción a un grupo determinado son privados de determinados bienes disponibles para los atros, cabe dentro de esa estrategia libcral promover medidas de discriminación positiva cuyo fin sea multiplicar las oportunidades de los individuos pertenecientes a esos grupos menos favorecidos y acortar distancias con los mejor situados haciendo efectivo el régimen de derechos iguales para todos y cada uno. Desde este punto de vista las medidas de discriminación positiva debieran ser concebidas y aplicadas de tal modo que su propia eficacia las volviera un día innecesarias haciendo que el trato preferencial hacia determinados grupos tuviera un horizonte temporal y una naturaleza instrumental ${ }^{21}$. De lo contrario, sus beneficiarios quedarían estigmatizados por un permanente sistema de cuotas asignadas a determinadas posiciones sociales; y de ese modo más que los individuos serían los grupos quienes se alzarian con 
«el derecho a tener derecho». Esto no significaría acomodar las diferencias, sino esencializarlas al precio de subordinar a los individuos. Un resultado de esta naturaleza sería, además, contradictorio con los postulados del feminismo ético de inspiración igualitaria $\mathrm{y}$, desde luego, con los principios de una teoría liberal y democrática de la justicia, con cuyos principios el primero está comprometido ${ }^{22}$.

\section{La Democracia como métrica de la Justicia}

El origen del liberalismo fue en cierta medida una apuesta por acomodar las diferencias. Pero andando el tiempo, se comprendió que no era suficiente «poner entre paréntesis» las diferencias, confinarlas en el ámbito de lo íntimo y hacerlas irrelevantes para el gobierno de la interacción, tal como pensaba Locke. El desarrollo posterior de la veta igualitaria en el seno de la tradición liberal vino a subrayar la enorme significación social y política de las diferencias, ya que algunas de ellas determinan la distribución de oportunidades y restricciones, derechos y deberes, beneficios y status $^{23}$. De ahi que la estrategia liberal tuviera que ser no sólo de acomodación, sino también de igualación, identificando aquellas diferencias socialmente relevantes para a la luz de los principios morales del liberalismo no sólo acomodar, sino en algunos casos cancelar o compensar las diferencias.

La mayor parte de las teorias de la justicia inspiradas en la tradición liberal, contractualistas, igualitaristas o utilitaristas, comparten los principios básicos de esa tradición. Pero ćproporcionan tales principios información suficiente para discernir qué méritos y capacidades hay que recompensar, qué igualdades hay que proteger y qué desigualdades eliminar? Además, puesto que los principios están expuestos a múl- tiples interpretaciones y las necesidades humanas son tan abundantes como escasos los recursos, la apelación a los principios no resuelve los conflictos de distribución, e incluso muchas veces las tensiones se avivan en nombre precisamente de uno u otro principio. Por eso las teorias de la justicia, por lo común, además de basarse en determinados principios, optan por valores más concretos, establecen algunas condiciones de viabilidad y definen ciertas referencias empiricas. Todo ello con el fin de dotarse de una métrica con la que obtener una información mayor para poder aplicar unos principios generales y más bien formales ${ }^{24}$. La hipótesis de la que partimos aquí es que los valores y procedimientos de la democracia son la métrica idónea para resolver las reclamaciones hechas al ideario liberal en nombre de la justicia, ya que el régimen democrático proporciona una mayor y más fiable información sobre dichas reclamaciones, unos criterios para ordenar dichas reclamaciones de un modo no contradictorio con los principios, $y$, en última instancia, la base política mâs plausible para un gobierno justo de las relaciones sociales.

Desde que hace más de veinte años J. Rawls justificara en su Teoría de la Justicia la semejanza entre requisitos de la justicia y procedimiento democrático, tanto sus partidarios como sus oponentes han compartido la creencia de que la idea del consenso es la intuición moral básica de ethos democrático ${ }^{25}$. Sin embargo, más que el consenso es la constatación del disenso en los diferentes dominios de la vida social lo que nos empuja a reclamar la democracia como sistema de gobierno justo de la interacción humana. Diariamente observamos la contraposición entre necesidades y recursos, entre preferencias de los individuos y posibilidades de satisfacerlas. Ninguna esfera de la vida está exenta de conflictos de poder y cualquier práctica social refleja desacuerdos entre 
los participantes bien sobre objetivos o bien sobre cómo llevarlos a la práctica. Por tanto, más que apelar al consenso como razón última de la democracia, deberiamos reconocer que, puesto que $\mathrm{cl}$ desacuerdo moral es endémico, el disenso en la vida social inevitable y los criterios de cómo ser gobernados dispares, no cabe otro procedimiento que el democrático para, en ausencia de un patrón moral único, resolver pacíficamente los conflictos y ordenar de un modo justo las prácticas sociales ${ }^{26}$.

Los rasgos de la democracia como métrica de la justicia se van forjando en una estrategia de negación, en la medida en que logra identificar lo que obstaculiza su desarrollo. En primer lugar, una concepción democrática de la justicia sospecha de toda jerarquia, sobre todo de aquellas que son permanentes (el sistema de castas en la India), asimétricas (la poligamia) y no fluidas, sino impuestas y arbitrarias 27 . El ethos democrático, además, es hostil al vanguardismo; no hay lugar en democracia para el jacobinismo o el iluminismo politico, nj para las pretensiones del experto que en razón de la excelencia de su conocimiento quiere imponer sus puntos de vista a la colectividad ${ }^{28}$. Por último, el ideal del autogobierno, uno dc los fundamentos éticos del régimen democrático, requiere que los afectados por las decisiones que se producen en un determinado ámbito puedan participar -derecho de inclusión-, proponer cambios -revisión del "status quon 29 - y tengan posibilidad de salida ${ }^{30}$.

¿Cabe aplicar un patrón de justicia, como el que acabamos de describir, a los distintos dominios de la vida social? En principio no parece que tenga que haber zonas francas para la democracia si no las hay tampoco para las desigualdades de poder $y$ las fucntes de dominación ${ }^{31}$. Sin embargo, llegados a este punto tradición liberal y estrategia democratizadora divergen. Desde un principio para la tradición liberal lo fundamental ha sido preservar para el individuo un perimetro de autonomía frente a la acción de los otros, promoviendo la «libertad negativa», la dicotomía público/privado y un gobierno limitado. Por el contrario, las tradiciones más democratizadoras han tratado de responder al hecho de la ubicuidad de las relaciones de poder y a su asimetría con programas de «inundación democrática». A estas alturas del desarrollo del programa político ilustrado se sabe, sin embargo, que muchos proyectos de extensión de la democracia han terminado simplemente en colonización política. En esa dirección no han faltado durante el presente siglo ejemplos para alimentar los recelos liberales.

Sin que entremos ahora a analizar a fondo las omisiones y excesos de una y otra posición, ambas adolecen de una misma confusión a propósito de lo que significa aplicar criterios democráticos en un ámbito social determinado. La democracia es un bien básico que debiera condicionar nuestras distintas prácticas sociales, y no hay razón en principio para eximir a ningún dominio de un gobierno democrático. Pcro el que la democracia esté en todo no significa que lo sea todo o que pueda anular la razón de ser de una esfera social concreta desnaturalizándola o suplantándola ${ }^{32}$. No tendria sentido, por ejemplo, que las relaciones de trabajo, el matrimonio o una comunidad religiosa dejaran de ser lo que son por el hecho de que criterios de justicia evalúen determinados extremos de tales instituciones. Como métrica de un principio de justicia la democracia debe quedar confinada a su condición de regla que regula aspectos concretos de distintas prácticas sin suplantarlas. ¿Debe incluso regular los hábitos de una comunidad como la familia, cuyos valores son la intimidad, la generosidad, la solidaridad y 
cuya economía es la del amor y el afecto? A dilucidar esta cuestión dedicaremos los próximos comentarios.

\section{La justicia en casa}

La familia ha sido $y$ sigue siendo una institución fundamental, un refugio donde muchas veces adultos y no adultos buscan refugio frente a un mundo externo hostil, el lugar donde los hijos desarrollan sus capacidades y donde todos sus miembros tratan de satisfacer cierta clase de necesidades psicológicas y emocionales. La vida familiar ejerce un impacto determinante en la evolución de las personas, siendo su influencia ineludible y su huella irreversible. La familia es desde una economía de consumo común y un lugar de la división del trabajo y producción de capital humano hasta un lugar para aprender y enseñar. Por otro lado, y tal como nos recucrda la información diaria, la vida familiar no es inmune a la dinámica de las relaciones de poder, del esposo sobre la esposa, de los padres sobre los hijos, ni es ajena a la expresión menos sutil de poder, la violencia. $Y$, sin embargo, el prejuicio liberal de la privacidad ha sancionado esa violencia o al menos la ha hecho permisiva, considerando que no cabe aplicar criterios de justicia a las relaciones familiares.

La razón por la que la mayoría de las teorías de la justicia no consideran a la justicia una virtud pertinente para regular las relaciones familiares es que en el seno de la familia se cultivan otro tipo de virtudes y además sus miembros comparten un mismo interés ${ }^{33}$. Tras esta generalizada creencia hay una concepción reduccionista de la justicia y una visión idealizada de la familia. En primer lugar, que en una comunidad como la familia puedan prevalceer los más nobles sentimientos no es razón para obviar los criterios de la justicia, ya que éstos garantizan en el sistema de relaciones de cualquier institución un mínimo moral básico. En segundo lugar, sólo si sentimentalizamos el idcal de familia, olvidaremos que en su seno se producen conflictos de intereses y de distribución, puesto que hay que repartir recursos limitados y decidir, por ejemplo, lo que se dedica a cducación, a seguros, a ocio, a atención sanitaria, por no hablar de la distribución de otros recursos menos tangibles como el afecto, la autoestima y el mutuo respeto. También en el seno de una familia se fijan objetivos y propósitos que no son a veces fácilmente reconciliables o realizables. La farnilia es, pues, una comunidad compleja, en la que se mezclan el conflicto y la cooperación, las cargas y los beneficios, las ventajas y las desventajas. Por eso el sentido de la justicia debe jugar en su seno un papel básico.

Tradicionalmente el patrón de distribución ha descansado en la autoridad patriarcal y sólo si se desmonta el reparto de funciones entre varón y mujer que descansa en la estructura patriarcal es factible introducir en la familia los valores de una concepción democrática de la justicia. Cuando en el ámbito doméstico los niños vean que su crianza y cuidado son compartidos tanto por el padre como por la madre, cuando los hombres participen, en pie de igualdad, en lo que hasta ahora ha sido el "reino de las mujeres», ese trajin diario que supone sentirse la responsable de todo tipo de necesidades de los más próximos, y cuando las mujeres se introduzcan de lleno en lo que hasta ahora ha sido el areino de los hombres", a saber, la actividad productiva, el gobierno de las instituciones y la creación intelectual, entonces los miembros de ambos sexos habrán desarrollado una nueva personalidad y considerarán deseable y viable una comunidad doméstica no condicionada por las diferencias de sexo y regulada por criterios de justicia como los que más arriba hemos señalado ${ }^{34}$. 
El otro argumento para la exención de la familia de las prescripciones de un ideal de justicia se encuentra, como apuntábamos más arriba, en la separación entre lo privado y lo público. Como se sabe, la originaria razón de ser de la propuesta liberal de separar privado y público era la de preservar una esfera de lo íntimo y lo personal, un perimetro de autonomía del individuo frente a la injerencia de la autoridad del Estado. Pero de tan razonable pretensión no se infiere, a juicio de la crítica feminista, el que se tenga que suspender todo juicio moral sobre el patrón de distribución entre hombre y mujer en el ámbito doméstico y dejar en penumbra la realidad de la dominación en el seno de la familia. «El reino de la libertad privada para el hombre, ha llegado a decir MacKinnon, es el reino de la subordinación colectiva de la mujer ${ }^{35} \ggg$.

Hoy en día el solapamiento entre ámbito doméstico y no doméstico es tan real como borroso y su interrelación tan penetrante como difusa. Por ejemplo, definir el ámbito doméstico como el espacio de la no interferencia del Estado resulta, cuando menos, cngañoso. La afirmación de que el Estado debe escoger entre intervenir o no en la familia carece de sentido. Las leyes del Estado juegan un papel fundamental en la configuración del matrimonio, en la formación y funcionamiento de la familia, en la determinación de sus límites, en la definición de la personalidad jurídica de sus miembros, y así un largo etcétera de ejemplos de intervenciones de lo estatal en el ámbito doméstico. Hasta cierto punto cabría decir que la familia misma va siendo conformada por decisiones políticas ${ }^{36}$. En un mundo en que una diversidad de poderes sin control interviene en todo y en todas partes, los recelos por las dimensiones del poder estatal han perdido enjundia. El poder del Estado, como cualquier otro, puede ser un instrumento de dominación, pero también puede contribuir a mitigarla, si es congruente con su naturaleza de poder regulado y controlado democráticamente ${ }^{37}$.

Es evidente, por último, que en el ámbito doméstico comienza nuestra experiencia de individuación y se produce nuestra socialización primera. El resultado empirico, según una abundancia de estudios psicosociológicos, es que la división de roles $\mathrm{y}$ funciones, así como la división del trabajo que se produce en el seno del ámbito familiar levanta barreras para la mujer en otras esferas de la vida social. En la esfera pública las mujeres se sienten percibidas también como mujeres, con la carga de prejuicios que eso conlleva ${ }^{3 \hat{\gamma}}$. A las mujeres, a diferencia de lo que les ocurre a la mayoría de los hombres, su cxpcriencia les enseña que ámbito doméstico y ámbito público no son mundos separados, sino indisolubles. ¿Cómo, entonces, no van a exigir las mujeres que los criterios de justicia alumbren el ámbito doméstico y se disuelva la sustancia de una dicotomía privado/público que al crear naturalezas y papeles distintos para hombres y nujeres entrega a los primeros la títularidad de lo público y a ellas la responsabilidad de lo privado generalizando asi su posición subalterna?

La conclusión, pues, de lo hasta aquí expuesto es que sin familia justa no hay sociedad justa. La cuestión es cómo aplicar en concreto los criterios de una concepción liberal y democrática de la justicia a un ámbito como el familiar sin desnaturalizar las prácticas constitutivas de dicho ámbito. En una cosa, sin embargo, coinciden las propuestas que comienzan a hacerse en esa dirección: para poder aplicar la concepción democrática de la justicia al ámbito doméstico es preciso alterar el actual régimen de relaciones matrimoniales y el sistema jerárquico patriarcal. Veámoslo, como punto final, en el ejemplo de alguna de esas iniciativas.

Si la capacidad de influencia de un individuo en el seno de un grupo y su vulnerabilidad se corresponden más o menos 
con las posibilidades de abandonarlo, es claro que el matrimonio supone para la mayoría de las mujeres una situación de asimetria de poder y vulnerabilidad ${ }^{39}$. La división del trabajo en el seno del matrimonio hace, por lo general, a la esposa más susceptible de ser explotada tanto en la relación matrimonial como en el trabajo fuera de casa. Pero esa vulnerabilidad se ha originado antes del matrimonio. Las condiciones en las que las mujeres se socializan crean una identidad femenina y un destino para las mujeres que hacen que las expectativas de futuro de éstas, sobre todo entre los grupos menos aventajados socialmente, estén vinculadas en una mayor o menor proporción a la perspectiva del matrimonio y a la doble responsabilidad del hogar y la educación de los hijos. Todo esto condiciona la formación, aprendizaje e incorporación de la mujer a un mercado de trabajo, cuya estructura no es ajena a la división sexual de funciones ${ }^{40}$. El matrimonio continúa el ciclo de la desigualdad, tanto en el seno de la familia como en el puesto de trabajo. Si la mujer no trabaja fuera de casa, su trabajo en ella no es reconocido, es decir, es trabajo impagado. Si trabaja fuera tiene que soportar una doble carga, la de dicho trabajo y las responsabilidades de lo domestico. En consecuencia, la desventaja es doble, tanto en casa por la desigual distribución de las responsabilidades domésticas entre marido y mujer como en el trabajo fuera, ya que sus oportunidades se ven disminuidas al competir con hombres que están exentos del trabajo doméstico. Esa vulnerabilidad de la mujer se agrava aún más una vez que el matrimonio termina: disminución de ingresos, pérdida de status, hijos a su cargo y necesidad de encontrar un trabajo. La experiencia del divorcio es para la mayoría de las mujeres la constatación más dura de su vulnerabilidad y la prueba de su dependencia -en muchos casos extrema dependencia económica- respecto al esposo. De ahí que el coste de salir para quien sufre la subordinación sea muy alto o incluso prohibitivo ${ }^{41}$.

Para combatir esta desigualdad de poder hay quienes defienden un régimen que equipare en términos económicos el valor del trabajo impagado que se realiza en el ámbito doméstico y el trabajo pagado desarrollado fuera. Para lograr un equal legal entitlement sobre todas las ganancias del matrimonio se propone legalizar la partición igualitaria entre marido y mujer de todos los ingresos devengados por el trabajo extradoméstico -equal splitting of wages-. Si se produce la eventualidad de un divorcio se procedería a un reparto igualitario y perdurable de la propiedad marital ${ }^{42}$. Puede que en la práctica nada varíe para muchas parejas con la adopción de esta fórmula. Sin embargo, este nuevo régimen de reparto reconoce legalmente que el trabajo, impagado, realizado en el ámbito doméstico es tan importante como el trabajo pagado que se desarrolla fuera, estableciendo de este modo una genuina igualdad de recursos dentro de la familia.

La debilidad de una propuesta de esta naturaleza es que no toma en consideración el conjunto de desigualdades que se producen fuera del ámbilo doméstico. Ésas quedan sin tocar. La distribución de oportunidades entre las mujeres se hace depender exclusivamente de los recursos y la posición del marido. Una misma clase de trabajo, el doméstico, termina teniendo un valor cconómico muy dispar, ya que su retribución varía a tenor de la posición social del marido. En resumen, si una estrategia de presión se focaliza en el esposo, la vulnerabilidad y las desigualdades de oportunidades de muchas mujeres no variarán sustancialmente.

Otra opción que cabe presentar como alternativa al régimen de familia patriarcal y congruente con una concepción democrática de la justica es que los adultos tengan una considerable libertad para decidir 
el tipo concreto de contrato que regule sus relaciones domésticas. ¿Por qué tiene que haber un único patrón de matrimonio para todos? ${ }^{43}$ Lo congruente con criterins democráticos de justicia sería, al parecer, que cl matrimonio se regulara conforme al régimen de contratación privada, estipulándose en cada contrato matrimonial sus condicioncs y contenidos específicos, los cuales habrían sido previamente pactados por las partes. Ciertamente una solución de esta naturaleza resolvería las justas quejas de tantas parejas "no ortodoxas" que se han visto privadas de los beneficios legales, asistenciales, laborales y fiscales del status matrimonial ${ }^{4 d}$. Pero para que el amparo legal no sc reduzca, sin más, al ultraliberal criterio de hacer cumplir lo pactado por las partes y si se quiere impedir que se pacte en condiciones de asimetría tal que los términos del contrato sean moralmente inaceptables y la situación resultante contraria a criterios de justicia, los poderes públicos tendrían que garantizar que los contratantes, tanto en el acuerdo prematrimonial como en el momento de su disolución, actúan libremente, es decir, tienen posibilidades reales de salida y unas capacidades básicas como para poder romper el círculo de la vulnerabilidad. Con esto, dada la situación generalizada de desigualdad entre muchas parejas por razón del sexo, la intervención subsidiaria y complementaria del Estado para garantizar unos mínimos sería muy frecuente devolviendo a la mayoría de las parejas a una situación parecida a la existente, cs decir, a la necesidad de acogerse a un tipo de contrato matrimonial standard indiciado y avalado por los poderes públi$\cos$.

Como se ve, la aplicación de una concepción liberal y democrática de la justicia al mundo familiar puede arrojar soluciones diversas y controvertidas. En unos casos se insiste más en las transformaciones que deberian producirse en cl seno de la estructura matrimonial para acomodarla a las exigencias de la justicia; en otros, el énfasis se pone en la necesidad de modificar la concepción contractual heredada de la institución matrimonial. Pero más allá del contenido concreto de unas u otras propuestas, lo relevante desde la perspectiva conceptual es que la filosofía política comienza a recuperar para el dominio de la teoría de la justicia el ámbito doméstico. De este modo un debate sin tabúes y liberado de ciertos prejuicios está abriéndose paso en la producción de pautas morales y normas legales, así como en la jurisprudencia, y se alumbra ya un fondo de convicciones, inédito hasta hace bien poco, que en el punto final de estos comentarios me atreveria resumir del siguiente modo: las familias en las que los papeles y las responsabilidades están igualmente repartidos sin atender a las diferencias de sexo son familias que han interiorizado los criterios de una concepción liberal y democrática de la justicia; una sociedad sin prejuicios sexistas, una sociedad que tiene en cucnta la realidad de madres, padres y niños en instituciones como el puesto de trabajo y la escuela y con una organización igualitaria de la vida familiar educará niños sin la restricción de expectativas determinada por las diferencias que marca el géncro, y proporcionará a las mujeres las mismas oportunidades que a los hombres para desarrollar sus capacidades más valiosas, para participar en el ejercicio del poder político, para influir en las decisiones sociales y para sentirse física y económicamente seguras. Ésa será la vía para que, como pedía Stuart Mill, la familia no sea considerada una escuela de despotismo, sino del desarrollo moral y un ámbito de aprendizaje de los hábitos de justicia. 


\section{NOTAS}

"John Stuart Mill, "The Subjection of Women"s en Collected Work, Toronto, University of Toronto Press, vol. 21, 1984

2 Principios de justicia, como el de tratar lo igual de forma igual y lo desigual de forma destgual o como el de dar a cada cual lo que se le debe, son prescripcioncs tan gencricas que poco ayudan a resolver los conflicios de distribución que toda teoria de la justicia tiene planteados. Lo que verdaderamente hace zelevante una concepción de la justicia es la información que la mistna proporciona para discernir qué, en concreto, se ke debe a cada cual y por qué algunas igualdades deben ser procuradas y ciertas diferencias erradicadas o compensadas. Sobre la base informativa de los criterios de justicia, véase Amarlya Sen, whformational Analysis of Moral Principlesw, en R. Harrison (ed.), Rational Action, Cambridge, Cambridge University Press, 1979; del misno autor, Inequality Reexamined, Cambridge, Mass., Harvard University Press, 1992, pp. 73-75; también Antoni Domenect, kMarx el'Etica», en Teoria Política, nún. 2, 1993, pp. 57-65.

- Catharine A. Mackinnon, Toward a Feninist Theory of the State, Cambridge, Mass., Harvard University Press, 1989, p. 238, y Javier Muguerza, «La sinnazón de la razón patriarcal: feminismo y filosofia en Celia Amorós", en La Balsa de la Medura, núm. 4, p. 7 .

- Victoria Sau, Ser mujer: El fin de una imagen tradicional, Barcelona, Icaria, 1986

- Linda J. Nicholson, Gender and History: The Limits of Social Theory in the Age of the Family. Nueva York, Columbia University Press, 1986, especialmente la introducción, y Carole Pateman, «Feminist Critiques of the Public/Private Dichotomy", en Stanley Benn y Gerald Gaus, Private and Public in Social Life, Londres, Croom Helm, 1983

- Susan Moller Okin, eGender, Inequality and Cultural Differencess, Political Theory, vol, 22, núm. 1 , 1994, pp. 10-11.

7 "El feminismo, dice Mackinnon, identifica la sexualidad como la primera esfera social del poder del varón... Cada elemento del estereotipo del género femenino se revela de hecho como algo sexual... Ser mujer se asimila a lo propiamente femenino, es decir, significa atracción sexual $y$, por tanto, disponibilidad sexual desde el punto de vista del vatón, Toward a Feminza Theory of the State, pp. 109-110. Véase tambiên Cass R. Stunstein, eIntroduction: Notes on Feminist Political Thought", Ethics, num. 99, 1989, p. 227.
"Susan Moller Okin, Justice, Gender and the Family, Nueva York, Basic Books, 1989, p. 5. Para una consideración más detallada sobre la construcción social del género véase el capítulo primero, pp. 3-24.

- Amartya Sen, "Equality of What? *, en Sterling M. MoMurrin (ed.), The Tanmer Lectures of Human Values, University of Utah Press, 1980, pp. 197.220; Sobre ética y economía, Madrid, Alianza Universidad, 1987, pp. 58.65 .

10 Celia Amorós, Hacia una critica de la razón patriarcal, Barcelona, Anthropos, 1985, pp. 103-104, 116, 129-130; de la misma autora, "Igualdad $\mathrm{c}$ Identidadw, en Amelia Valcárcel (comp.), El concepto de Igualdad, Madrid, Editorial Pablo Iglesias, 1994, pp. $29-48$.

1 Rogers M. Smith, ante United People: Second Class Female Citizenship and the American Quest for Community", Yate Joumal of Law and the Humanities, vol. $1,1989, \mathrm{pp} .288-292$. Una defensa del «eminismo de la igualdad» desde la perspectiva de un demoeratismo más radical en Chantal Mouffe, The Retum of the Political, Inondres, Vcrso, 1993, p. 82.

12 Catharine A. Mackinnon, Toward a Feminist Theory of the State, Cambridge, Harvard University Press, 1989 , pp. $238,125,163-165$.

13 La tesis básica de la escuela crítica se rcsume en que el detechnes un reflejo de las relaciones de poder y de su asimetria: Ruberto Unger, «The Critical Legal Studies Movement", Hanard Legal Review. núm. 96, 1983. Para un juicio adverso de la escuch critica del Derecho, véase Owen M. Fiss, kiLa mucrte del Derecho?s, Doxa, núm. 10, 1991, pp. 132-140. Fiss se hat opuesto específeamente a una superposíción de escuela critica y leminismo, ya que, a su juicio, una buena parte de éste ha mostrado en los últirnos años una mayor confianza on las perspectivas icformistas del Derecho como cauce del ensanche de la justicia, como puede verse en su otro articulo «El derecho recuperadon, Doxa, núm. 11, 1992, pp. 240-246.

14 Iris Marion Young, «polity and Group Difference: A Critique of the Ideal of Universal Citizenships», Ethics, núm. 99, 1989, pp. 250-274, y Nancy Fraser, *Toward a Discourse Ethics of Solidarity" Praxis Intemational, num. 5, 1986 , pp. 425-429.

is Carol Gilligan, In a Different Voice: PsychoIngiant Theory and women's development, Cambridge, Mass., Harvard University Press, 1982, pp. 65-105, 154-160.

16 Se denomina "dilema de la diferencia a la tensión que vive la conciencia feminista entre impulso igualitario y afirmación de la propia identidad leme- 
nina. Mientras lo primero empuja a ncgar difercncias esenciales entre hombres y mujeres para que no exista justificación de la privación a las mujeres de un conjunto de oportunidades y del acceso a posiciones que disfrutan los hombres, lo scgundo invita a descchar un igualitarisnto que supone tanto aceptar la concepción patriarcal de la ciudadanía como renunciar a la afirmación de la propia identidad, fuente de auténticas necesilades y reclamacionss congruentes con la condición femenina. Un buen resumen del estado de la cuestion en Chantal Mouffe, The Retum of the Political, pp. $85-86$.

17 Carole Pateman, The Serual Contract, Stanford, Stanford University Press, 1988, pp. 224-231; Iris Marion Young, Polity and Group difference: A Criticute of the ldeul of tiniversal Difference, pp. 257, 261-262; también de ta misma autora, Justice and the Politics of Difference, Princeton, Princeton University Press, 1990 .

is J. Donald Moon, \&Rights and the Accomodation of Difference» (en prensa), y Kirstie M. McClure, "Difference Diversity and the Limits of Toleration", Poltical Theory, vol. 18, num. 3, 1990, pp. 361-391.

19 Los objetivos de una ética de la justicia se definen mejor por el «mal que se trata de cvitar que por «el bien» que se invita a alcanzar. $Y$ como dice M. Walzer, antes que nada deberiamos repudiar como el primer ma! social aquel estado de cosas que niega los principios y normas sin los cuales no es posible que forezan y estén protegidas cuałquier concepción de uvida buenaw: Michael Walzer, «Nation and Universe», The Tanner Lechures On Human Values, 1990 , p. 535 .

3* La terminologia es de Martin Golding, «Towards a Theory of Human Rights", The Monist núm. 52, 1986, pp. 521-549. Pero quien desde hace tiempo viene profundizando en la diferencia entre basic capabiltiles y recursos ha sido Amartya Sen, el cual en uno de sus ultimas libros sigue insistiendo en la idea de gue los recursus son importantes, pero aún más las posibilidades de las personas para clegir autónomamente, para desarrollar la esfera de su soberania individual: Inequalio Recramined, pp. 5672, 79-87.

2) Para un conocimicnto del debate térico sobre la disctiminación positiva sigue siendo basica la obta colectiva editada por Murshall Cohen, Thomas Nagel y Thomas Scanlon, Equality and Preferencial Treament, Princeton, Princeton University Fress, 1977. También M. Rosenfeld, Affimative Action and Justice, New Haven, Yale University Press, 1991. Una aproximación critica es Seymour Martin Lipset, «Equal Chances ver- sus Equal Results*, Annals, AAPSS, nüm. 523, 1992, pp. 63-74.

$22 \mathrm{El}$ «feminismo de la igualdad» considera pura mistificación el interés del "feminismo de ka diferencia" por esencializar la «identidad femenina», ya que dicha identidad ha funcionado como principio de subordinación precisamente al endosar a la mujer uná especial inclinación a lo natural, concreto, intuitivo y privado frente a un varón dotado particularmente para lo cúto. lo abstracto, to reflexivo y lo publico. En esta dirección, véase Amelia Valeárcel, Sexo y Filosofía, sobre wMitjen. $y$ «oden;, Barcelona, Anthropos, 1901, pp. 54-56, 169-184.

${ }^{2}$ Kristie Mcclure, Difference, Diversity and the Limits of Torelation, pp. 384-386.

za lan Shapiro, aThree ways to be a democrats, Political Theory, vol. 22, num. 1, 1991, p. 127. Por ejemplo, la utilidad es la métrica del utilitarismo clásico y su principio el de máxima felicidad; los bienes hásions son la métrica de J. Rawls al tiempo que los principios se encuentran en su concepción general y particular de la justicia; para $M$. Walzer la métrica es la piuralidad de las esferas y el rechazo de la dominación es el principio de su concepción de la justicia.

zs John Rawls, A Theory of Justice, Cambridge, Mass., Harvard University Press, 1971 (traducción en Mexico, Fondo de Cultura Económica, 1977). $\Lambda$ pesar de la indudable repercusion de las cricicas en la transformación pusterior de la concepción de Rawls, sin embargo, la inspiración hásica de la misma en torno a la idea de consenso permanece inalterable, tal como puede comprobarse cu su último libro, recopilacion de las revisiones más recientes a las que Rawis ha sometido a su tcoria: Political Liberalism, Nueva York, Columbia University Press, 1993.

* Ian Shapiro, Political Criticism, Berkeley, University of California Press, 1990, pp. 266, 270 y 282.

7 bid. pp. 277-279.

* ibid. pp. 283-284.

29 Robert Dahl, Democracy and its critics, New Haven, Yale University Press, 1989, pp. 120-129.

* La negación de la posibilidad de salida se produce en la dase de relaciones que son, sin escapatoria, en las que no hay libertad para abandonar la sítuación dada, o bien el precio para haccrlo es mu alto. Quien, como se sabe, inspiró un enfoque general en esta dirección fue Albert Hirschman a partir de su conocida obra Exil, Voice and Loyalty (Cambridge, Haryard University Press, 1979). Pero para el análisis de la implicación más precisa entre compromisos no voluntarios y justicia vease Thomas Scanlon, ePreference and 
urgency", The Joumal of Philosophy, vol. LXXI, núm. 19, 1975, pp. 664-666.

"Michael Walzer, Spheres of huttice: A Defense of Phoralism and Equality, Nueva York, Basic Books, 1983, pp. 10-11.

32 Robert Dahl, After the Revolution, New Haven, Yale University Press, pp. 68-79, 96-121, y Chantal Mouffe, The Retum of the Political, pp. 71-72. Un útil resumen sobre la literatura participacionista y sus paradojas en Carmen Sirianni, Panticipation, Cambridge University Press (en prensa), cap. 1.

33 Rousseau ya habia expresado que la justicia no era una virtud idónea para la familia. En cl contexto de la discusión presente sobre la teoria de la justicia ha sido Michael Sandel en su sugestiva obra por otros conceptos, Liberalism and the Limits of Justice, Cambridge, Cambridge University Press, 1982, pp. 31-35, quicn ha argumentado que la familia está «más allá» de la justicia por su elevada condición moral.

${ }^{34}$ Susan M. Okin, Jasice, Gender and the Family, cap. 2, pp. 105-107.

35 Toward a Feminist Theory of the State, p. 168. Alison Jaggar, Feminist Politics and Human Nature, Totowa, N. J., Rowman and Allanheld, 1988. La radicalización de la denuncia de la división público/privado bajo cl lema de que sko personal es político y lo político personals avivó, sobre todo en Estados Unidos, durante lus años sesenta y setenta, un movimiento contra la familia quc orilló al núcleo reformista de la crítica feminista al tirmpo que daba munición abundante a las opiniones maăs conservadoras en relación con este debate. Véase en ese sentido: Juklith Stacey, «Are Feminist Afraid to Leave Home? The Challenge of Conservative Pro-family Feminist», en What is Feminism? A Rexamination, Julict Mitchell y Ann Oakley, Nueva York, Pantheon, 1986.

${ }^{36}$ Frances E. Olsen, *The Myth of Statc Intervention in the Familyn, University of Michigan Joumal of Law Reform, 18, núm. 4, 1985, pp. 837-864.
${ }^{77}$ Migue] Ángel Quintanilla y Ramón Vargas-Machuca, La Utopia Racional, Madrid, Espasa-Calpe, 1989, caps. VIII y XI.

3s En un régimen de libertad de expresión, como sun nuestras democracias liberales, el poder de la palabra mide en cierta medida la autoridad de una persona. Muchas mujeres en sus intervenciones públicas tienen la certeza de que su palabra cuenta menos, por lo que su posición es devaluada y en consecuencia su voz exchuida de la autoridad. Es lo que trata de demostrar Kathleen Jones en su interesante estudio de la relación entre mujer y autoridad: $\alpha O n$ Authority: $O r$, why women are not entitled to Speaks, en J. R. Pennock y J. W. Chapman, Authority Revisited, Nueva York, Nueva York University Press, 1987.

${ }^{37}$ Robert E. Goodin, Protecting the Vulnerable: A reanalysis of Our Sacial Responsibilites, Chicago, Chicago University Press, 1985, pp. 197, 189m191, y Susan Okin, Justice, Gender and the Family, p. 142.

* Susan M. Okin, Justice, Gender and the Family, pp. 143-146.

${ }^{41}$ Leonore J. Weitzman, The Ditorce Revolution: The Unexpected Socinl an Economic Consequences for Women and Chitdren in America, Nueva York, The Free Press, 1985.

42 Susan M. Okin, Justice, Gender and Family, pp. $180-181$.

43 Sobre la peculiar naturaleza contractual que la legislación vigente otorga al matrimonio, véase Catole Pateman, The Sexuat Contract, Stanford, Stanford University Press, 1988, caps. 5 y 6. Llama la atención la crítica feminista del rechazo legal a los contratos entre los cónyuges y advierte de la incongruencia del contrato matrimonial con los principios contractualistas de la doctrina liberal, ya que las partes no son libres para establccer los términos del contrato y además tienen restricciones a la hora de elcgir el partner.

44 Una propuesta destinada a defender una mayor libertad contractual de los cónyuges a la hora de determinar el régimen de relaciones en el ámbito dornéstico la desarrolla Ian Shapiro en el capitulo eThe domestic domain: Adult telations* de su libro Democratic Jlastice (en prensa). 